\title{
THE IMPORTANCE OF PAY IN EMPLOYEE MOTIVATION: DISCREPANCIES BETWEEN WHAT PEOPLE SAY AND WHAT THEY DO
}

\author{
Sara L. Rynes, Barry Gerhart, and Kathleen A. Minette
}

\begin{abstract}
A majority of human resources professionals appear to believe that employees are likely to overreport the importance of pay in employee surveys. However, research suggests the opposite is actually true. We review evidence showing the discrepancies between what people say and do with respect to pay. We then discuss why pay is likely to be such an important general motivator, as well as a variety of reasons why managers might underestimate its importance. We note that pay is not equally important in all situations or to all individuals, and identify circumstances under which pay is likely to be more (or less) important to employees. We close with recommendations for implementing research findings with respect to pay and suggestions for evaluating pay systems. (C) 2004 Wiley Periodicals, Inc.
\end{abstract}

It is easy to overestimate the frequency with which adults actually go to the opera and underestimate the frequency with which they watch TV cartoons on Saturday mornings, based on their self-reports. (Nunnally \& Bernstein, 1994, p. 383)

Rynes, Colbert, and Brown (2002) presented the following statement to 959 members of the Society for Human Resource Management (SHRM): "Surveys that directly ask employees how important pay is to them are likely to overestimate pay's true importance in actual decisions" (p. 158). If our interpretation (and that of Rynes et al.) of the research literature is accurate, then the correct true-false answer to the above statement is "false." In other words, people are more likely to underreport than to overreport the importance of pay as a motivational factor in most situations. Put another way, research suggests that pay is much more important in people's actual choices and behaviors than it is in their self-reports of what motivates them, much like the cartoon viewers mentioned in the quote above. Yet, only $35 \%$ of the respondents in the Rynes et al. study answered in a way consistent with research findings (i.e., chose "false").

Our objective in this article is to show that employee surveys regarding the importance of various factors in motivation generally produce results that are inconsistent with studies of actual employee behavior. In particular, we focus on well-documented findings that employees tend to say that pay

Correspondence to: Sara L. Rynes, Tippie College of Business, 108 PBB, University of Iowa, Iowa City, IA 52242-1000, tel.319-335-0838, Sara-Rynes@uiowa.edu

Human Resource Management, Winter 2004, Vol. 43, No. 4, Pp. 381-394

(c) 2004 Wiley Periodicals, Inc. Published online in Wiley InterScience (www.interscience.wiley.com).

DOI: $10.1002 / \mathrm{hrm} .20031$ 
In general, there appears to be a consistent (but incorrect) message to practitioners that pay is not a very effective motivator-a message that, if believed, could cause practitioners to seriously underestimate the motivational potential of a well-designed compensation system. is less important to them than it actually is. This is an important point because if employees' reports are taken at face value, HR professionals are likely to seriously underestimate the motivational potential of pay. Moreover, a quick survey of the journals or magazines that are most often read by practitioners (in particular, HR Magazine for HR professionals and Harvard Business Review for general managers) suggests that they, too, tend to take employee surveys at face value without carefully examining the behavioral evidence related to pay and motivation.

In the section that follows, we first present evidence demonstrating the gap between what people say and what they do with respect to pay. We then show that practitioner journals present claims about pay importance that are inconsistent with research about the actual motivational effects of pay. In general, there appears to be a consistent (but incorrect) message to practitioners that pay is not a very effective motivator-a message that, if believed, could cause practitioners to seriously underestimate the motivational potential of a well-designed compensation system.

\section{Gaps between What People Say and Do with Respect to Pay}

Table I presents findings from a number of major studies that have attempted to determine the importance of pay to employees, relative to other potential motivators. In the first column are the results of studies that have simply asked people to rate or rank pay's importance, relative to other potential motivators. In the right-hand column are the results of studies in real, ongoing organizations that examine differences in work output following implementation of various motivational interventions: modifications of pay systems, work redesign, increases in employee participation, and enhanced performance feedback. In order to increase the reliability of the conclusions drawn, we included only studies that are either narrative reviews of the literature, meta-analytic reviews (which incorporate the data from many individual studies into a single large-scale empirical analysis), ${ }^{1}$ or single studies with very large sample sizes (e.g., Jurgensen [1978], which had over 50,000 respondents, and Towers Perrin [2003], which had over 35,000].

As the first column of Table I shows, when asked directly about the importance of pay, people tend to give it answers that place somewhere around fifth (range $=$ second to eighth) in lists of potential motivators. In contrast, meta-analytic studies of actual behaviors in response to motivational initiatives (second column) nearly always show pay to be the most effective motivator. Indeed, after conducting the first such meta-analysis with respect to motivational interventions, Locke, Feren, McCaleb, Shaw, and Denny (1980) concluded: "Money is the crucial incentive ... no other incentive or motivational technique comes even close to money with respect to its instrumental value" (p. 379). Subsequent research has continued to support their conclusion.

Why do such discrepancies occur, and how can psychological theories help us explain them? The common tendency for people to say one thing but do another is known as socially desirable responding: "the tendency to choose items that reflect societally approved behaviors" (Nunnally \& Bernstein, 1994 , p. 382). Social desirability stems from either a lack of self-insight or a lack of frankness (Nunnally \& Bernstein, 1994). In the case of pay, people are likely to understate importance either because they misjudge how they might react to, say, an offer of a higherpaying job, or due to social norms that view money as a less noble source of motivation than factors such as challenging work or work that makes a contribution to society.

Generally speaking, the more a particular question touches on strongly held social values, the less valid direct self-reports are likely to be. In such cases, both managers and researchers must find additional ways of ferreting out more valid information. Recognizing this, some researchers have approached the topic of pay importance by examining how employees' behaviors (such as turnover or performance) change in response to changes in pay and other HR practices (e.g., the second column in Table I). These behavioral responses are far more compelling pieces of evidence than people's 
Major Studies of Self-Reported Pay Importance

1. Herzberg, Mausner, Peterson, and Capwell, 1957. Literature review of 16 studies showed that pay ranked sixth in importance. Ranking above pay were job security, interesting work, opportunity for advancement, appreciation, and company and management.

2. Lawler, 1971. Reviewed 49 studies showing that pay ranked approximately third across studies. Did not list rankings for other motivators.

3. Jurgensen, 1978. Collected rankings of importance from more than 50,000 applicants to the Minneapolis Gas Company over a 30-year period. Pay ranked fifth in importance to men, and seventh in importance to women. For men, security, advancement, type of work, and company ranked higher than pay. For women, type of work, company, security, supervisor, advancement, and coworkers ranked higher.

4. Towers Perrin, 2003. Surveyed more than 35,000 U.S. employees. Found importance of pay varies by objective. Competitive base pay ranked second and pay raises based on individual performance ranked eighth for attracting employees. Competitive base pay ranked sixth in retaining employees. Pay was not ranked in the top ten in terms of "engaging" (motivating) employees.
Major Studies of Behavioral Responses to Pay and Other Motivational Interventions

1. Locke, Feren, McCaleb, Shaw, and Denny, 1980. Metaanalysis (see Note 1 at end of article) of productivity-enhancing interventions in actual work settings found that introduction of individual pay incentives increased productivity by an average of $30 \%$. In contrast, job enrichment produced productivity increases ranging from 9-17\%, while employee participation programs increased productivity by less than $1 \%$, on average.

2. Guzzo, Jette, and Katzell, 1985. Meta-analysis of monetary incentives and other motivational programs on productivity or physical output. Financial incentives had by far the largest effect on productivity of all interventions. For example, pay was four times more effective than interventions designed to make work more interesting.

3. Judiesch, 1994. Meta-analysis found that individual pay incentives increased productivity by an average of $43.7 \%$. Results were even larger $(48.8 \%)$ when the sample was restricted to studies in real organizations (as opposed to laboratory experiments). Other interventions were not studied, but we know of no meta-analysis that has presented findings for other motivational interventions that come close to approaching these effect sizes.

4. Stajkovic and Luthans, 1997. Meta-analysis found that incentive systems yielded productivity 1.36 standard deviations higher than in comparable groups without incentives in manufacturing firms (comparable figure in service firms was .42). Similar effect sizes were found for feedback and social rewards.

5. Jenkins, Mitra, Gupta, \& Shaw, 1998. Meta-analysis of relationships between financial incentives and performance quantity and quality. Found an average correlation of .32 between incentives and quantity of production, but no reliable relationship between incentives and product quality. responses to surveys regarding what is "important" to them. As Table I shows, on average, employees respond more effectively to monetary incentives than to any other motivational $\mathrm{HR}$ intervention.

The presence of socially desirable responding has been revealed using a number of other research techniques as well. For example, one common psychological research strategy is to adopt projective techniques (e.g., asking what people think others probably think or do, or asking them to create a motivational story from an ambiguous picture) to draw out sensitive or threatening in- formation. A creative example of this approach was implemented by Jurgensen (1978), who assessed the relative importance of ten job characteristics (including pay) to 50,000 job applicants over a 30-year period by asking them to "decide which of the following [job attributes] is most important to you" (p. 268). Based on these direct responses, males reported pay to be only the fifth most important factor, while women reported it to be even lower (seventh; see Table I). However, when Jurgensen asked the same men and women to rank the importance of the same ten attributes to "someone just like 
The systematic underestimation of pay's importance, both by managers and employees, is a puzzle that merits examination. yourself-same age, education, and gender," pay jumped to first place among both men and women. In other words, job applicants seemed to believe that pay is the most important attribute to everyone except themselves!

A second creative technique, called "policy capturing," examines how people evaluate the attractiveness of holistic job alternatives (i.e., entire "bundles" of job characteristics, such as pay, location, type of work, and benefits) in order to tease out the relative contribution that pay and other characteristics make to their overall assessments. The use of holistic job descriptions presents a situation much closer to the decisions job seekers actually make about prospective jobs than asking them to rate or rank a list of abstract, decontextualized job characteristics. By measuring each job in terms of its underlying characteristics (i.e., level of pay, location, type of work, average time to promotion) and then comparing those characteristics with people's overall ratings of job attractiveness, the importance of each underlying job characteristic to overall attractiveness can be inferred without asking direct questions about importance.

In such studies, pay has generally been found to be a substantially more important factor when inferred via policy capturing than when assessed via people's direct reports (Barber, 1998; Rynes, Schwab, \& Heneman, 1983; Schwab, 1982). For example, Feldman and Arnold (1978) found that pay was fourth out of six job attributes (opportunities to use important skills and abilities was first) when graduate business students were asked to rank them from "most preferred to least preferred" (p. 707). In contrast, when using policy capturing with "willingness to accept the position" as the outcome variable and the six job attributes as the predictor variables, they found that pay's "importance weight" was largest and nearly twice as large as that of the next job attribute.

In summary, there is strong evidence that pay is a powerful motivator-perhaps the most powerful potential motivator-of performance. (We say "potential" motivator because in order to motivate, pay must be noticeably contingent on performance-a condition that does not hold in many organ- izations; more on this later.) However, the study by Rynes et al. (2002) suggests that managers do not believe pay is as important to employee behaviors as employees say it is, despite the fact that employees themselves appear to seriously underreport pay's importance to their actual behaviors! The systematic underestimation of pay's importance, both by managers and employees, is a puzzle that merits examination.

We have already noted that one potential explanation for these discrepancies is social desirability - the idea that to be motivated by money is somehow "crass" or undignified. Another explanation, however, may lie in the kinds of information that HR professionals receive about pay in the most widely read practitioner journals. A review of these journals shows that articles about motivation are based on the types of survey evidence presented in the first column of Table I, rather than the behavioral evidence reported in column two. As such, it is perhaps not surprising that practitioner journals tend to widely disseminate the idea that pay is not a very important motivator.

Consider, for example, the February 2004 issue of HR Magazine, the periodical that Rynes et al. (2002) found to be far and away the most frequently read source of information by HR professionals. The cover story, called "Getting Engaged" (Bates, 2004), reports on two recent surveys of employee "engagement," defined as the "bases for ... an innate human desire to contribute something of value to the workplace." Roughly, then, engagement would appear to have much in common with the psychological construct of motivation.

The first survey, by Towers Perrin (2003), identified ten factors influencing engagement. In contradiction of the meta-analytic evidence presented earlier, pay was not even on the list. (The top four were senior managers' interest in employees' well-being, challenging work, decision-making authority, and customer focus.) A Towers Perrin principal was quoted as saying, "A lot of the drivers of engagement are subtle issues that don't require a lot of capital outlay. They take work" (Bates, 2004, p. 64). ${ }^{2}$ Similarly, the second survey (by Walker Information) reported the 
top five factors with the "greatest influence on an employee's commitment to a firm" (note that commitment is not the same as motivation). Again, pay was not on the list.

A similar tendency to publish viewpoints arguing against the importance of pay exists in other practitioner resources as well. Consider, for example, the Harvard Business Review, which has a circulation of a quartermillion and tends to be read by high-level executives who are in charge of corporate strategy. A review over the past 12 years reveals the following titles: "Why Incentive Plans Cannot Work" (Kohn, 1993, who goes on to explain "why bribes simply cannot work"), "Six Dangerous Myths about Pay" (Pfeffer, 1998, which claims it is a "myth" that individual pay-for-performance is an effective motivator), and "One More Time: How Do You Motivate Employees?" (Herzberg, 1987, whose answer basically is "not with pay, because pay is actually a demotivator"). Moreover, in introducing a recent special issue of HBR on "The Most Tangible Assets" (i.e., employees), the "From the Editors" section identified two overarching themes of the articles, one of which was that "we learn that while traditional rewards and punishments can, if ill managed, severely damage motivation, they have little beneficial effect under even the best of circumstances." These claims are simply inconsistent with the voluminous evidence, based on hundreds of studies, exemplified in the second column of Table I. (For a more extensive treatment of these and other research distortions, see Gerhart \& Rynes, 2003.)

In summary, research on employee responses to HR interventions shows rather convincingly that pay is a very important motivator. The most general theoretical explanation for pay's importance is the fact that it is useful for obtaining so many other desirable things (Lawler, 1971). For example, in addition to Maslow's (1943) frequently mentioned "lower-order" needs (such as food and shelter), money can also pave the way toward social status, a good education for one's children, or making it possible to retire early and enjoy increased leisure.

Another general explanation for the importance of pay is that pay is frequently used as a yardstick for social status (Frank, 1999) and personal accomplishment vis à vis others, particularly among high achievers (Trank, Rynes, \& Bretz, 2002). Status- and accomplishment-based signals associated with compensation appear to be particularly sensitive to relative pay, or pay comparisons, rather than absolute levels of pay. Equity theory (Adams, 1963) has long emphasized the importance of pay comparisons to individuals' sense of fairness and well-being. More recently, sociobiologists and evolutionary psychologists have built a compelling case that the importance of relative wealth and status is "hard-wired" in human nature-the result of evolutionary and natural selection processes that favor (in terms of procreational success) those who come out "on top" in a positional or hierarchical sense. Thus, we find that people are often motivated to buy houses or yachts that are "just a little bigger" than those of some close comparator (Frank, 1999), or to demand that their salaries always be "just a little bit higher" than the highest current salary among their peers (e.g., Crystal, 1991).

In summary, the broad usefulness of money as well as its many symbolic meanings suggests that, far from being a mere loworder motivator, pay can assist in obtaining virtually any level on Maslow's motivational hierarchy, including social esteem and selfactualization.

\section{Contingency Factors: The "It Depends" Nature of Pay Importance}

To this point, we have presented evidence suggesting that pay is a very important motivator, despite employee self-reports and persistent articles in practitioner journals that suggest otherwise. In fact, meta-analytic results do not reveal any motivational interventions that work better than performancecontingent pay for enticing people to attain higher performance levels.

However, in emphasizing the importance of pay as a motivator, we are not saying that pay is the only important motivator. Indeed, it is clear that many of the other factors mentioned by researchers such as Maslow and Herzberg (for example, interest-
The broad usefulness of money as well as its many symbolic meanings suggests that, far from being a mere loworder motivator, pay can assist in obtaining virtually any level on Maslow's motivational hierarchy, including social esteem and selfactualization. 
Research suggests that individual payfor-

performance

schemes (e.g., merit pay,

individual

incentives, or

bonuses) are

most important

to high

academic

achievers, high-

performing

employees, and

individuals

with high self-

efficacy and

high needs for

achievement-

just the types of

people most

employers

claim to be

looking for! ing work and participation in decision making) are also important motivators to many people, as confirmed in the empirical results shown in both columns of Table I. Thus, we recommend that multiple motivators-for example, performance-based pay and challenging work-be used in conjunction with one another as they are in such successful firms as Microsoft and General Electric, or firms that use open book management practices (a combination of complete financial information sharing, companywide performance-based pay, and high levels of employee involvement in decision making; see Case, 1998).

In addition, we are not saying that pay is always the most important motivator or that pay is equally important in all situations. Although meta-analytic results can tell us about motivational effects "on average," they cannot tell us what is appropriate for a particular manager to do in a given situation. Most managers (correctly) believe that the importance of pay depends on a number of variables, both situational (e.g., what others are paying) and individual (e.g., personality or performance level). This same point has also been made by academics. For example, economists have emphasized that attribute importance can only be determined in concrete choice situations where various job characteristics are assumed to be traded off against each other to reach the highest overall utility (Rottenberg, 1956). Similarly, psychologists have noted that individual differences in personality and performance also influence the attention given to pay in behaviors and decisions (e.g., Trank et al., 2002; Trevor, Gerhart, \& Boudreau, 1997).

Space limitations preclude us from discussing all the contingencies that appear to affect the importance of pay in a given situation (for a more complete summary, see Gerhart \& Rynes, 2003). However, some of the most interesting or consistent findings are presented in Table II, which is broken down into "individual difference" and "situational" contingencies.

On the individual differences front, we think it is very important to note the types of individuals who are most likely to prefer pay that is contingent on performance. Specifi- cally, research suggests that individual payfor-performance schemes (e.g., merit pay, individual incentives, or bonuses) are most important to high academic achievers, highperforming employees, and individuals with high self-efficacy and high needs for achievement (e.g., Harrison, Virick, \& Williams, 1996; Trank et al., 2002; Trevor et al., 1997; Turban \& Keon, 1993)_just the types of people most employers claim to be looking for! In addition, pay is more important to extroverts than to introverts (e.g., Stewart, 1996), while pay relative to peers is of higher importance to individuals who have held more leadership positions in college (Trank et al., 2002). Once again, these are the types of employees-those with "people" and leadership skills-that most companies seem to be looking for.

We think these findings are important, particularly in light of the currently predominant advice suggesting that employers reduce the relationship between individual pay and performance (e.g., Herzberg, 1968/2003; Kohn, 1993; Pfeffer, 1998). Although there are some reasonable notions behind such recommendations (e.g., to encourage teamwork), it is important to consider that some of the most sought-after and desirable employees do not wish to work in systems that do not differentiate individual performance. Indeed, the average U.S. worker desires individual (rather than teamor organization-based) pay-for-performance (e.g., Bureau of National Affairs, 1988), with high performers desiring it to an even greater extent (e.g., Trank et al., 2002).

There are also a number of interesting findings on the situational side of Table II. Some of the most important of these can be summarized in terms of four general principles. The first such principle is that in order for pay to be an important motivator, there has to be variability in pay options. For example, consider an applicant's job choice decision. Taken to the extreme, a person faced with several job alternatives, all at the same pay and benefit levels, would indeed find that salary was not "important" to his or her job choice. Likewise, if employees in the same job at the same company all receive highly similar "merit" increases despite noticeable 


\section{TABLE II Illustrative Examples of Contingency Factors Affecting Pay Importance}

\section{Individual Difference Contingencies}

1. Pay is more important to extroverts than to introverts (Lucas, Diener, Grob, Suh, \& Shao, 2000; Stewart, 1996).

2. Receiving performance-based pay is more important to high academic achievers than to others. Receiving higher pay than their co-workers is more important to extroverts and individuals with a history of social achievements (e.g., leadership positions; Trank, Rynes, \& Bretz, 2002).

3. High-performing employees appear to be particularly sensitive to whether their higher performance is rewarded with above-average pay increases, while low performers prefer low-contingency pay systems (e.g., Harrison, Virick, \& Williams, 1996; Trevor, Gerhart, \& Boudreau, 1997).

4. Pay appears to be more important to men than to women (e.g., Hollenbeck, Ilgen, Ostroff, \& Vancouver, 1987; Jurgensen, 1978; Mincer \& Polachek, 1974).

5. People with high need for achievement and higher feelings of self-efficacy prefer pay systems that more closely link pay to performance (e.g., Bretz, Ash, \& Dreher, 1989; Turban \& Keon, 1993).

\section{Situational Contingencies}

1. Pay is more important in job choice when pay varies widely across employers than when pay is relatively more uniform (Rynes, Schwab, \& Heneman, 1983).

2. There is a declining marginal utility to additional increments of pay. This means that, dollar for dollar, being "under market" has a stronger deterrent or demotivational effect than the positive effect of paying above market. People often reject low-paying job offers on the basis of pay alone, without considering other factors (Rynes, Schwab, \& Heneman, 1983).

3. The salience or "importance" of pay is likely to rise after changes are made to pay systems. Employees are particularly sensitive to pay cuts. For example, Greenberg (1990) showed substantial increases in employee theft when employees were subjected to pay cuts.

4. Employee reactions to changes in pay depend heavily on communication of the reasons for pay policies and changes. For example, Greenberg observed a $141 \%$ increase in theft when a $15 \%$ pay cut was made without explanation, as compared with only a $54 \%$ increase in theft in a plant where workers received an adequate explanation and where managers expressed remorse.

5. Pay is probably more important in job choice than in decisions to quit, in part because pay is one of the few characteristics people can know with certainty before taking a job. In contrast, once a person has been on the job for awhile, other factors (such as quality of supervision) come into play (Rynes et al., 1983; Towers Perrin, 2003).

6. Pay will do little to motivate performance in systems where people receive similar pay increases regardless of individual or firm performance. However, dramatic changes in performance often occur when pay is made more contingent on performance (see column 2, Table I). differences in performance (a rather common situation, by most accounts), managers will similarly conclude that pay is not effective in motivating people.

However, it is important to recognize that in these examples, pay is not motivating because it is not being used in a way that would be expected to produce motivation. In both scenarios, pay would be expected to play an important role if opportunities for pay varied significantly across employers, or across individuals of varying performance levels within the same employer. The importance of pay variability in influencing pay importance has been demonstrated empirically under carefully controlled conditions. For ex- ample, Rynes et al. (1983) showed that pay explained an average of $65 \%$ of the variance in subjects' overall evaluations of job attractiveness when presented with jobs having a wide range of salary alternatives, as compared to only $40 \%$ when presented with a pay range half as great.

The fact that the importance of pay changes with variability in pay alternatives can also be seen by contrasting the effects of pay in vibrant versus stagnant economies. During the late 1990s, for example, the importance of pay in shaping behavior could easily be observed as many of the most marketable employees bailed out of large, relatively stable employers to pursue much 
Every time employers make pay changes, employees are on "high alert" for changes that might signal differences in how they are regarded by the employer, particularly in relation to peers or to their own past relationship with the employer. higher upside earnings opportunities (via stock options and grants) at smaller, highgrowth companies. Indeed, before the slowdown in 2000, large numbers of MBA students were leaving such elite universities as Harvard before completing their degrees in order to take advantage of the dot-com and Silicon Valley bubbles. Retaining information technology professionals became extremely difficult for many employers, as companies continually outbid each other in an effort to secure scarce talent in a booming economy. But these effects dampened considerably as the economy collapsed and employers no longer had to bid employees away by offering higher salaries and increased variable pay.

A second general principle is that the motivational effect of money is nonlinear across pay levels. This phenomenon is reflected in the economic principle of "declining marginal utility," which suggests, for example, that the opportunity to earn an additional $\$ 100$ will be more motivating to an individual at the poverty level than to someone earning $\$ 100,000$ per year. Another important example of nonlinear pay importance is the concept of a reservation wage in job choice-a level of pay that must be met before an individual will even consider accepting a job offer. Thus, companies that fall considerably below market in terms of starting salaries will find that this lower threshold of acceptability will be a rather severe impediment to applicant attraction, while those who are near the middle of the market will find that factors other than pay begin to play a much larger role in applicants' job choices.

A third principle is that people judge the fairness of pay in relative terms. Equity theory (Adams, 1963) posits that individuals assess the fairness of their pay by comparing their own ratio of inputs (e.g., effort and skill) and outcomes (pay, recognition) to the input-outcome ratios of important "comparison others" such as close coworkers, workers in other companies, or the employee's past work history. The theory also predicts that an individual who perceives her raise to be inequitable is likely to change her behavior in one of several ways: expressing dissatisfaction to her supervisor, working harder to get a bigger raise next year, working less to bring her inputs in line with her perceived outcomes, or quitting in disgust.

One implication of the importance of comparative standards and past practices to employees' sense of justice is that employees react strongly to changes in pay that affect their standing relative to some important standard (e.g., the past, or a coworker perceived to be a close rival for future advancement). As such, every time employers make pay changes, employees are on "high alert" for changes that might signal differences in how they are regarded by the employer, particularly in relation to peers or to their own past relationship with the employer. Psychological contract perspectives likewise recognize the key role that pay has in the broader employment relationship, noting that "the meaning of compensation systems is far broader than mere economic terms, signaling much about the nature of the employment relationship" (Rousseau \& Ho, 2000, p. 304).

For example, pay level will clearly become "important" and affect employee behaviors if it is cut, particularly if employers do not communicate a convincing reason for the change (e.g., Greenberg, 1990). Indeed, most managers have at least an implicit understanding of this psychological dynamic in that they appreciate the extreme sensitivity of the decisions they make concerning pay and how it is communicated. Unfortunately, awareness of employees' sensitivity to pay often causes managers to shrink from openly communicating about it (Lawler, 1981), despite the fact that direct communication can be very important in terms of making employees feel that decisions were fairly arrived at and in motivating future performance (e.g., Greenberg, 1990; Prince \& Lawler, 1986).

The fourth principle is that the importance of pay tends to differ depending upon whether the objective is attraction, retention, or on-the-job performance. In addition, different dimensions of pay differentially affect these three objectives. As an example of the first point, pay level is likely to be quite important both in attracting employees (e.g., Rynes et al., 1983) and in retaining them 
(e.g., Delery, Gupta, Shaw, Jenkins, \& Ganster, 2000; Guthrie, 2000). However, it is likely to be relatively more important in attraction than retention (Towers Perrin, 2003; see column 1, Table I). This is because pay is one of the few job characteristics that can be known with certainty at the point of job choice. In contrast, other important factors (such as the quality of management or the camaraderie among coworkers) may not be known until one has been on the job for some time (Rees, 1973). As such, these other factors are likely to become relatively more important in the decision of whether to leave an employer than they are in job choice.

To the second point (that different dimensions of pay differentially affect different outcomes), applicant attraction and retention are probably most heavily influenced by pay level, or the extent to which employees receive higher or lower pay than similar workers at other companies. ${ }^{3}$ However, once employees have decided to accept a job, pay levels will not be much of a factor in how hard they work (with the partial exception that if the pay level is noticeably above-market, most employees will probably work hard enough not to get fired). The aspect of pay that will most directly motivate performance, however, will be the extent to which pay is contingent on performance. Thus, if raises are barely differentiated on the basis of performance, then it should not be at all surprising to find little influence of pay on motivation. In contrast, as meta-analytic evidence shows, when pay is sharply differentiated on the basis of performance, pay is a very effective motivator indeed.

We cannot emphasize this last point enough. To this point in the article, we have suggested that practitioners generally underestimate the motivational potential of pay because of socially desirable responding by employees in surveys and misinformation in the practitioner press. However, it is now time to add a third possibility - that most practitioners work in companies where the differential rewards for performance are so small, or so well concealed, that employees are not in fact motivated by money. However, this is not because employees can't be motivated by money, but rather because they do not believe that higher performance will result in noticeably more money. Observers of pay practices have long noted that characteristics of so-called "merit pay" systems generally result in only minuscule performance-based raise differentials among employees, with the bulk of the raise pool being distributed very closely around the "average" increase level. In this respect, most privatesector employees are not all that different from government employees, whose general level of efficiency is bemoaned by taxpayers due to the fact that they have "no incentive" for better performance.

In summary, although pay has strong motivational potential, its actual effectiveness as a motivator depends on a variety of individual and situational factors, including the way it is administered in practice. We turn now to a discussion of how practitioners can incorporate the findings from this research into their compensation systems.

\section{Implementing General Principles from Compensation Research}

The preceding evidence leads to the following suggestions:

- Take complaints about pay seriously. Given that there is a general social norm against revealing that one is motivated by pay (at least in nonunionized situations), when an employee does indicate pay dissatisfaction, it is generally a cause for concern. This assumes, of course, that you actually want to retain the individual.

- Do not fall very far below market pay levels. It is more disadvantageous to be "way below market" than it is advantageous to be "way above" it. Being noticeably below market will cause some applicants, often the most desirable ones, to reject your offer out of hand. However, once you reach market levels, choices will generally be made on a multidimensional basis, where factors other than pay can also become competitive advantages (or disadvantages).
The aspect of pay that will most directly motivate performance... will be the extent to which pay is contingent on performance. Thus, if raises are barely differentiated on the basis of performance, then it should not be at all surprising to find little influence of pay on motivation. 


\author{
Although most \\ nomunionized \\ and \\ nongovernment \\ employees are \\ ostensibly paid \\ on the basis of \\ merit, \\ examination of \\ most \\ companies' pay \\ systems reveals \\ little \\ differentiation \\ in raises \\ between \\ average and \\ superior \\ performers.
}

- Realize that most of the best employees want strong pay-performance relationships. On average, the ability to earn a lot of money for outstanding performance is a competitive advantage for attracting, motivating, and retaining high-performing employees. This is not to say that organizations cannot attract good employees without high-contingency systems; clearly, a number of well-known firms have done so (e.g., SAS software). However, in such cases, the absence of contingent pay is compensated by a strong culture emphasizing other values and benefits (in SAS's case, familyfriendliness, as well as high general pay levels and benefits). In addition, there are also a number of organizations that thrive on high companybased (versus individually based) contingent pay, such as Southwest Airlines or Nucor Steel. These companies are able to attract high performers who also hold relatively strong collectivist values.

- Evaluate current pay systems with respect to the strength of pay-performance relationships. Although most nonunionized and nongovernment employees are ostensibly paid on the basis of merit, examination of most companies' pay systems reveals little differentiation in raises between average and superior performers. Pay-performance contingencies are generally limited by such practices as setting job grade ceilings and paying for nonmerit considerations (e.g., external equity adjustments or matching competing offers) out of the "merit" pay budget. Similarly, pay-performance contingencies should also be evaluated at the supra-individual level: Are there gain-sharing or profitsharing programs? If so, are the payouts large enough, immediate enough, or frequent enough to make a difference to how hard people are willing to work? (For exam- ple, deferred profit-sharing plans that are designed as substitutes for defined benefit pensions are unlikely to have a motivational effect.) Finally, examine how closely pay-increase budgets mirror changes in organizational performance levels. Many employees have become quite used to being told that the annual increase budget will be very modest due to limited ability to pay (i.e., low corporate profitability). However, the reverse is often not true, with raise pools remaining modest even in years of high profitability and the remaining money being allocated elsewhere.

- Examine whether executive pay is moving in the same direction, and at roughly proportionate rates, as employee increases. Evidence from the past 30 years reveals quite convincingly that in the typical corporation, the ratio between executive and nonexecutive compensation has increased to a very substantial degree. Not only has the earnings gap between executive and nonexecutive employees exploded over the past several decades (Bok, 1993; Crystal, 1991; Frank \& Cook, 1995; Shulman, 2003), but there are also many examples of disproportionate increases in executive pay in the face of poor organizational performance (Samuelson, 2003; Useem, 2003). Because how people feel about their pay is a result of comparative processes, organizations with huge variance between executive and employee pay practices are likely to be populated with workers eagerly awaiting opportunities to move to other organizations. (An important side note is that workers are often accepting of very high executive pay, such as Bill Gates at Microsoft or General Electric under Jack Welch, so long as the fruits of strong organizational performance are also passed on to lower layers of the organization.) 


\section{Evaluating the Effectiveness of Pay Systems}

After following the general design principles outlined in the preceding section, how can an organization evaluate the success of its compensation policies and practices? One of the most important suggestions to emerge from the reviewed research is that one needs to track employee behaviors as well as employee attitudes. On the behavioral side, there are at least three outcomes that are likely to be heavily affected by compensation practices: attraction, retention, and performance. Each of these outcomes should be closely monitored to detect problems with the compensation system.

For example, with respect to attraction, is a company's job acceptance rate higher or lower than those of other companies in its area or industry? If lower, are applicants accepting positions with higher or lower starting salaries? In addition, what types of applicants and employees are being lost - the most desirable or the least? Similar questions should be asked about retention. (A good example of monitoring turnover by employee performance levels can be found in Trevor et al. [1997].) Also, in both cases, outcomes should be tracked in relation to previous years, as well as to benchmark firms or competitors. Different results suggest different kinds of solutions.

Similar kinds of tracking should be done with respect to employee performance. Because most firms do not have objective measures of individual performance, performance outcomes must often be tracked at team, department, or plant levels. Of particular interest are changes in performance associated with major changes in HR practices, such as shifting from individual to team production or from merit pay to gain sharing.

Although assessing employee behaviors is crucial to evaluating effectiveness, there are still reasons to monitor employee attitudes as well. In particular, changes in satisfaction or importance levels are often leading indicators of subsequent changes in behavior. As such, employee surveys can still be a valuable part of the evaluative arsenal.

Previous research has shown that responses to employee surveys (e.g., which items are rated as more "important" or "satisfying" than others) can be heavily dependent on such things as the precise wording and format of the questions asked (Lawler, 1971). Therefore, managers should use highly similar surveys from year to year and pay considerable attention to changes in responses to key questions having to do with pay importance, pay fairness, and pay satisfaction. If the implicit contract regarding pay level, pay-for-performance, or any other aspect of pay has changed (due either to actual changes in practice or to a changing market or workforce conditions), a good survey should be able to capture this.

In particular, the responses and reactions of the top performers should be carefully monitored. Of course, employee survey data are typically anonymous, so direct links to performance data may not be feasible. However, self-reported performance on employee surveys can be used. Additionally, the turnover rates of high performers can be compared to those of other employees.

Employers can also be more proactive in anticipating and heading off certain problems (e.g., eroding pay levels) by using salary surveys to benchmark their pay level and other pay practices against other organizations. Finally, realizing that people may not always be forthright in exit interviews about their reasons for leaving, one should ask directly what they will be earning in their new job as a way of gauging the extent to which pay might be a determining factor.

\section{Conclusion}

Money is not the only motivator and it is not the primary motivator for everyone. However, there is overwhelming evidence that money is an important motivator for most people. Further, there is ample evidence that surveys asking people to rank order money and other motivators do not accurately reflect the important effects that changes in pay levels or the way pay is determined actually have on people's decisions to join and leave organizations. Likewise, the oftenmodest survey rankings are at odds with behavioral evidence on the powerful effects that monetary incentives have on the goals
One of the most important suggestions to emerge from the reviewed research is that one needs to track employee behaviors as well as employee attitudes. 
that people choose to pursue within organizations and the effort and commitment they exert toward those goals. Thus, while managers will (and should) consider both financial and nonfinancial tools for attracting, motivating, and retaining employees, it would be a mistake to conclude, based on general surveys, that monetary rewards are not highly important. Finally, as we have demonstrated, the importance (or potential importance) of monetary rewards in any particular situation can be evaluated by considering both the situational variables (e.g., pay variability) and individual variables (e.g., performance level) that best describe the context of a particular manager's decision.

The empirical evidence we have presented here is highly consistent with the mo- tivational views of former CEO Jack Welch, who is widely acknowledged to have breathed new life into a well-respected, but somewhat "sleepy," General Electric. Changing GE's pay system to provide much higher rewards for strong individual and organizational performance was one of the pivotal tactics in Welch's overall strategy for revitalization and growth:

I think showering rewards on people for excellence is an important part of the management process. There's nothing I like more than giving big raises . . . You have to get rewarded in the soul and the wallet. The money isn't enough, but a plaque isn't enough either. . . . you have to give both. (Jack Welch, quoted in Hymowitz \& Murray, 1999, p. B1)

Sara L. Rynes is the John F. Murray Professor of Management and Organizations at the University of Iowa. Her research interests include staffing, compensation, and knowledge transfer between academics and practitioners. Rynes is incoming editor of the Academy of Management Journal and has served on the editorial boards of Journal of Applied Psychology, Personnel Psychology, and Frontiers in Industrial and Organizational Psychology. She is a Fellow of the American Psychological Association and the Society for Industrial and Organizational Psychology. Prior to moving to Iowa, she was on the faculties of the University of Minnesota and Cornell University.

Barry Gerhart is the John and Barbara Keller Distinguished Chair of Business at the University of Wisconsin-Madison. His research interests are human resource management and strategy, compensation, and business performance. In 1991, Professor Gerhart received the Scholarly Achievement Award from the Human Resources Division, Academy of Management. He is a Fellow of the American Psychological Association and the Society for Industrial and Organizational Psychology. Professor Gerhart is coauthor of the recent book, Compensation: Theory, Evidence, and Strategic Implications, as well as coeditor of Compensation in Organizations, and coauthor of Human Resource Management: Gaining a Competitive Advantage, now in its fourth edition.

Kathleen A. Minetre is presently vice president of human resources with Pearson, having joined the organization in 1994. Her undergraduate degrees in sociology and journalism are from Drake University, and her master's degree in organizational communication is from the University of Northern Iowa. Ms. Minette holds lifetime certification as a Senior in Human Resource Management (SPHR) from the Human Resources Certification Institute (HRCI). She presently sits on the HRCI board of directors as the Western Regional Examination Development Director. She teaches human resource management as an adjunct professor in the Tippie College of Business at the University of Iowa. 


\section{NOTES}

1. Meta-analysis is a method that combines effect size estimates from previous studies to increase sample size and thus yield better estimates of the mean and variance of the population effect size.

2. Note in Table I that the complete Towers Perrin report does show pay to be in the top ten for both attraction (second) and retention (sixth). However, these findings are not reported in $H R$ Magazine.

3. There can also be some effect of pay basis-i.e., the bases for pay increases, such as seniority, merit, gain sharing, or profit sharing-on applicant attraction and retention, since highachieving applicants and employees often seek companies that differentially reward for high performance (Towers Perrin, 2003; Trank et al., 2002; Trevor et al., 1997).

\section{REFERENCES}

Adams, J. S. (1963). Toward an understanding of inequity. Journal of Abnormal Psychology, 67, 422-436.

Barber, A. E. (1998). Recruiting employees. Thousand Oaks, CA: Sage.

Bates, S. (2004, February). Getting engaged. HR Magazine, 49(2), 44-51.

Bok, D. C. (1993). The cost of talent: How executives and professionals are paid and how it affects America. New York: The Free Press.

Bretz, R. D., Jr., Ash, R. A., \& Dreher, G. F. (1989). Do people make the place? An examination of the attraction-selection-attrition hypothesis. Personnel Psychology, 42, 561-581.

Bureau of National Affairs (1988). Changing pay practices: New developments in employee compensation. Washington, DC: Author.

Case, J. (1998). The open-book experience. Reading, MA: Addison-Wesley.

Crystal, G. S. (1991). In search of excess: The overcompensation of American executives. New York: Norton.

Delery, J., Gupta, N., Shaw, J., Jenkins, G. D., \& Ganster, D. (2000). Unionization, compensation, and voice effects on quits and retention. Industrial Relations, 39, 625-646.

Feldman, D. C., \& Arnold, H. J. (1978). Position choice: Comparing the importance of organizational and job factors. Journal of Applied Psychology, 63, 706-710.
Frank, R. H. (1999). Luxury fever: Why money fails to satisfy in an era of excess. New York: The Free Press.

Frank, R. H., \& Cook, P. J. (1995). The winner-takeall society: How more and more Americans compete for ever-fewer and bigger prizes, encouraging economic waste, income inequality, and an impoverished cultural life. New York: The Free Press.

Gerhart, B., \& Rynes, S. L. (2003). Compensation: Theory, evidence, and strategic implications. Thousand Oaks, CA: Sage.

Greenberg, J. (1990). Employee theft as a reaction to underpayment inequity: The hidden cost of pay cuts. Journal of Applied Psychology, 75, 561-568.

Guthrie, J. P. (2000). Alternative pay practices and employee turnover: An organizational economics perspective. Group \& Organization Management, 25, 419-439.

Guzzo, R. A., Jette, R. D., \& Katzell, R. A. (1985). The effects of psychologically based intervention programs on worker productivity: A metaanalysis. Personnel Psychology, 38, 275-291.

Harrison, D. A., Virick, M., \& Williams, S. (1996). Working without a net: Time, performance, and turnover under maximally contingent rewards. Journal of Applied Psychology, 81, 331-345.

Herzberg, F. (1987, September-October) One more time: How do you motivate employees? Harvard Business Review, pp. 5-16 (Reprint 87507).

Herzberg, F. (2003, January). One more time: How do you motivate employees? Harvard Business Review, pp. 3-11. (Original work published 1968)

Herzberg, F., Mausner, B., Peterson, R. O., \& Capwell, D. F. (1957). Job attitudes: Review of research and opinion. Pittsburgh: Psychological Service of Pittsburgh.

Hollenbeck, J. R., Ilgen, D. R., Ostroff, C., \& Vancouver, J. B. (1987). Sex differences in occupational choice, pay, and worth: A supply-side approach to understanding the male-female wage gap. Personnel Psychology, 40, 715-743.

Hymowitz, C., \& Murray, M. (1999, June 21). Boss talk: Raises and praise or out the door-How GE's chief rates and spurs his employees. Wall Street Journal, p. B1.

Jenkins, D. G., Jr., Mitra, A., Gupta, N., \& Shaw, J. D. (1998). Are financial incentives related to performance? A meta-analytic review of empirical research. Journal of Applied Psychology, 83, $777-787$. 
Judiesch, M. K. (1994). The effects of incentive compensation systems on productivity, individual differences in output variability and selection utility. Unpublished doctoral dissertation, University of Iowa.

Jurgensen, C. E. (1978). Job preferences (What makes a job good or bad?). Journal of Applied Psychology, 63, 267-276.

Kohn, A. (1993, September-October). Why incentive plans cannot work. Harvard Business Review, pp. 54-63.

Lawler, E. E., III. (1971). Pay and organizational effectiveness: A psychological view. New York: McGraw Hill.

Lawler, E. E., III. (1981). Pay and organizational development. Reading, MA: Addison-Wesley.

Locke, E. A., Feren, D. B., McCaleb, V. M., Shaw, K. N., \& Denny, A. T. (1980). The relative effectiveness of four methods of motivating employee performance. In K. D. Duncan, M. M. Gruenberg, \& D. Wallis (Eds.), Changes in working life (pp. 363-388). New York: Wiley.

Lucas, R. E., Diener, E., Grob, A., Suh, E. M., \& Shao, L. (2000). Cross-cultural evidence for the fundamental features of extraversion; Journal of Applied Psychology, 79, 452-468.

Maslow, A. H. (1943). A theory of human motivation. Psychological Review, 50, 370-396.

Mincer, J., \& Polachek, S. (1974). Family investments in human capital: Earnings of women. Journal of Political Economy, 82, S76-S108.

Nunnally J. C., \& Bernstein, I. H. (1994). Psychometric theory (3rd ed.). New York: McGraw-Hill.

Pfeffer, J. (1998). Six dangerous myths about pay. Harvard Business Review, 76, 108-120.

Prince, J. B., \& Lawler, E. E. (1986). Does salary discussion hurt the developmental performance appraisal? Organizational Behavior and Human Decision Processes, 37, 357-376.

Rees, A. (1973). The economics of work and pay. New York: Harper and Row.

Rottenberg, S. (1956). On choice in labor markets. Industrial and Labor Relations Review, 9, 183-199.

Rousseau, D. M., \& Ho, V. T. (2000). Psychological contract issues in compensation. In S. L. Rynes \& B. Gerhart (Eds.), Compensation in organi- zations: Current research and practice (pp. 273-310). San Francisco: Jossey-Bass.

Rynes, S. L., Colbert, A., \& Brown, K. G. (2002). HR professionals' beliefs about effective human resource practices: Correspondence between research and practice. Human Resource Management, 41, 149-174.

Rynes, S. L., Schwab, D. P. \& Heneman, H. G. (1983). The role of pay and market pay variability in job application decisions. Organizational Behavior and Human Performance, 31, 353-364.

Samuelson, R. J. (2003, May 5). Welfare for capitalists. Newsweek, p. 54.

Schwab, D. P. (1982). Recruiting and organizational participation. In K. M. Rowland \& G. R. Ferris (Eds.), Personnel Management (pp. 103-128). Boston: Allyn \& Bacon.

Shulman, B. (2003). The betrayal of work: How lowwage jobs fail 30 million Americans and their families. New York: The New Press.

Stajkovic, A. D., \& Luthans, F. (1997). A meta-analysis of the effects of organizational behavior modification on task performance, 1975-1995. Academy of Management Journal, 40, 1122-1149.

Stewart, G. L. (1996). Reward structure as a moderator of the relationship between extraversion and sales performance. Journal of Applied Psychology, 81, 619-627.

Towers Perrin. (2003). Working today: Understanding what drives employee engagement. The 2003 Towers Perrin Report.

Trank, C. Q., Rynes, S. L., \& Bretz, R. D. (2002). Attracting applicants in the war for talent: Differences in work preferences among high achievers. Journal of Business and Psychology, 17, 331-345.

Trevor, C. O., Gerhart, B., \& Boudreau, J. W. (1997). Voluntary turnover and job performance: Curvilinearity and the moderating influences of salary growth and promotions. Journal of Applied Psychology, 82, 44-61.

Turban, D. B., \& Keon, T. L. (1993). Organizational attractiveness: An interactionist perspective. Journal of Applied Psychology, 78, 184-193.

Useem, J. (2003, April 28). Have they no shame? Fortune, pp. 58-64. 